How to Cite

Estevez, G. A., Espinosa, A. H. R., \& Rodríguez, D. L. (2019). Design of intervention program for preventing of alcohol misuse in university students. International Journal of Health \& Medical Sciences, 2(1), 33-38. https://doi.org/10.31295/ijhms.v2n1.86

\title{
Design of Intervention Program for Preventing of Alcohol Misuse in University Students
}

\author{
Galano Ailén Estevez \\ Universidad de Oriente, Santiago, Cuba \\ Corresponding author email: ailen.galano@nauta.cu \\ Ana Hortensia Rodríguez Espinosa \\ Villa Colibrí Therapeutic Community, Santiago, Cuba \\ Email: a.hortensia@nauta.cu \\ Dilka Leyva Rodríguez \\ Universidad de Oriente, Santiago, Cuba \\ Email: talimar81@gmail.com
}

\begin{abstract}
In the Universidad de Oriente of Santiago de Cuba, recent diagnoses showed there is currently an increase in the rate of young people who consume alcoholic beverages. Therefore, the present research has like General Objective: To design a psychoeducational intervention program to prevent the undue consumption of alcohol in the Student Residence of the University of the East of Santiago de Cuba. Techniques such as Composition, Risk Perception Questionnaire on Alcohol Consumption, Social Skills Questionnaire and Preference Questionnaire for leisure time have used. The main results were that $94 \%$ of these young people had a low perception of risk on alcohol consumption and only $15 \%$ were able to identify the main negative consequences associated with consumption. $96 \%$ had insufficient development of social skills, which is associated with the poor ability to resist the pressure of the group.
\end{abstract}

Keywords---alcohol consumption, psychoeducational intervention, risk perception.

\section{Introduction}

The consumption of psychoactive substances or drugs is currently one of the most serious problems from a psychological, physiological and spiritual point of view that humanity has had to face. This situation is even more alarming due to the fact that the average age of consumers has declined in recent years, reaching multiple countries in the ages of adolescence and youth, including Cuba.

Of all these drugs, alcohol is the most consumed in the world, considered as a model carrier drug for the initiation of the consumption of other illegal substances and whose abusive use has led to a complex problem of public health, dependence and alcohol addiction (González \& Galán, 2007). The region of the Americas, along with Europe, according to the World Health Organization reports in 2014, has the highest rates of alcohol consumption worldwide.

A recent study by the Pan American Health Organization (PAHO), the WHO regional office for the Americas, includes Cuba among the countries that have the highest mortality rates due to causes attributable to alcohol, which reflects the harmful patterns of consumption (MINSAP, 1997). These data show that alcohol is one of the most widely used addictive substances in Cuba. To this fact is added the increase in ingestion among adolescents, there being a sustained decrease in the age of the first contact with this substance (Aghara et al., 2018; Ekawati et al., 2017; Ekawati et al., 2017).

Consequently, as part of the preventive projection of the National Health System, there is an urgent need to design psychosocial intervention strategies aimed at the psychotherapeutic approach of addictive behaviors and the realization of strategies aimed at eliminating or minimizing this problem in the spaces where insert adolescents and young people, occupying an important place in the educational field (Ministry of Higher Education, 2014).

The Universidad de Oriente is not unaware of this action, has a strategy for the prevention of drug abuse and control, developed in 2001 and updated each academic year by the multidisciplinary team of work consisting of 
professors and university workers (Universidad de Oriente, 2001). This has allowed an approach to the problem, but it still does not solve the actual situation of risk, because diagnoses made recently by the Department of Psychology in the Student Residence (Mazorra \& Galano, 2014) show that in recent years there has been an increase in the index of young people who consume alcoholic beverages since $76 \%$ of young people are consumers.

The study shows that of them, $61 \%$ are included in the categories of social consumers and $39 \%$ are consumers of the risk. To this problem, it is added that the consumption of alcoholic beverages affects the coexistence in the Residence since its adverse effect includes dangerous verbal and even physical offenses among the students, in addition to negative effects on the consumer such as sleep disorder and problems. Learning. The situation described above demonstrates the need that exists to carry out actions aimed at eliminating or minimizing alcohol consumption in the Student Residence of the Universidad de Oriente, since this substance is the only legal and non-medical drug capable of affecting the conscience and the personality, as well as provoking the disastrous interpersonal and social consequences associated with the most noxious drugs known to date (González, 2012).

In this sense, prevention activities are one of the actions that have the best results in the reduction of undue alcohol consumption. Consequently, this posed Research Problem following: How to contribute to the prevention of undue consumption of alcohol in university students in the Student Residence of the Universidad de Oriente in Santiago de Cuba?

It is proposed as a General Objective. Design a psychoeducational intervention program to prevent the undue consumption of alcohol in the Student Residence of the Universidad de la Oriente in Santiago de Cuba.

The present study has great importance because it responds to the contents established by the Ministry of Education through its Director Program of Promotion and Education for Health in the National Education System, where anti-alcohol education has established among the fundamental thematic axes and antidrug in a general sense.

In addition, the research is convenient as one of the priorities that have established in the Educational Work of the Student Residence of the Universidad de Oriente. Is to achieve the social and personal development of the students through the acquisition of healthy lifestyles, by which justifies the need to prevent the consumption of alcohol since in its capacity as a porter it can stimulate the consumption of illegal drugs in those with more vulnerable lifestyles (Estevez et al., 2019; 2018).

\section{Material and methods}

The research was based on the qualitative paradigm; qualitative methodology and group theory have used. In this way, the reflection group has integrated as a group device with psychodramatic and participative resources, to create reflective spaces that enable the modification of stereotypes, questioning of beliefs and patterns of behavior, the search for new alternatives, the formation of new knowledge and the assumption of attitudes of rejection to alcohol consumption. The intervention program was designed in 7 sessions of group work in which the Reflection Group was used, as a group tool that facilitates the conscious, critical and active expression of the subjects in each of the sessions.

\section{Subjects of investigation}

A group of 15 students has formed who met the following selection criteria: belonging to the first year of the Electrical Engineering degree and presenting risk consumption. The groups of students that have identified with the greatest risk of consumption in the Student Residence, so that it diminishes and prevents them from reaching abusive consumption, based the reasons for this selection on the need to begin to carry out prevention.

\section{Variables and theoretical indicators}

a) Perception of risk on alcohol consumption: is the estimation of risk according to perception, which has a cognitive and emotional component, and is associated with the perception of the degree of danger and the negative effects of alcohol consumption (García, 2012).

Indicators:

1) Domain about the real consequences that alcohol consumption produces.

2) Beliefs associated with alcohol consumption.

3) Stereotypes associated with alcohol consumption.

4) Attitudes assumed before the consumption of alcohol. 
b) Social skills: specific skills required effectively perform a task. They are conducts necessary to interact and relate to others in an effective and mutually satisfactory way (Monjas, 2012). The social skills required in situations of alcohol supply are associated with the ability to resist the pressure of the group, ability to communicate with the group to explain and defend their own opinions and behaviors as well as the ability to make decisions.

Indicators:

1) Autonomy in decision-making.

2) Coping and resistance to pressure by the group.

3) Assertive communication with the group.

c) Leisure habits: a set of satisfying and rewarding activities of a physical, cultural, social and practical nature that have has carried out frequently during the free time of each person, being decided by oneself and managed autonomously.

Indicators:

1) Physical leisure activities: have aimed at achieving personal rest and restoring psychological balance, the most frequent being those that have a physical-sporting nature.

2) Cultural leisure activities: they are oriented to the development of activities and intellectual knowledge, such as reading books, attending the theater and concerts, exhibitions and museums, etc.

3) Social leisure activities: they revolve around interpersonal relationships and associationism since for their realization individuals have to cooperate and collaborate with each other in specific contexts.

4) Leisure activities of practical nature: behaviors that have a utilitarian purpose, such as gardening, shopping and visiting shopping centers, techniques applied to the Collection of information.

d) Risk Perception Questionnaire on Alcohol Consumption

Objective: To determine the perception of risk existing in young people about alcohol consumption, taking into account the theoretical indicators that were defined to evaluate this variable.

e) Composition "About the consumption of alcoholic beverages I think ..."

Objective: To assess the perception of risk on alcohol consumption through the analysis of beliefs, stereotypes associated with the consumption of alcoholic beverages, as well as the attitudes assumed by young people towards said consumption.

f) Social skills questionnaire and decision making

Objective: Evaluate social skills linked to the decision making autonomy, the ability to resist pressure by the group and assertive communication.

g) Questionnaire on preferences for leisure time

Objective: Determine which activities are preferably carried out by young people during leisure time.

\section{Form of evaluation of the results}

The evaluation system was based on the principles of the methodological paradigm used, on proposals coming from the theory of the Pichón Rivière groups and on the theoretical indicators of the variables of the study. A qualitative evaluation has carried out in each of the group work sessions taking into account the following aspects:

a) A thematic or descriptive analysis of the group discourse (analysis of the explicit): it consists of the analysis of the contents that have addressed in each session, of the beliefs, the myths, and the proposals made by the research subjects, as well as the most discussed topics and those that are absent or omitted.

b) A dynamic or interpretive analysis of the group process (analysis of the implicit): consists in the unveiling of the underlying aspects of the elaboration of the theme of each session: the anxieties, resistances, emergencies, silences, fears provoked by the theme in each one of the moments of the session as well as an assessment of the group development indicators.

\section{Results and Discussion}

The initial diagnosis that was made in the group made it possible to identify that $94 \%$ of these young people have a low perception of risk on alcohol consumption, which was associated with their insufficient knowledge about the harmful effects of alcohol consumption. substance. Only $15 \%$ of young people were able to identify the main negative consequences associated with consumption, the rest was only able to enunciate some consequences for the physical health of the consumer, but failed to assess the effects from the psychological and social point of view. 
They identified the existence in the group of myths associated with alcohol consumption such as:

a) alcohol is a stimulant

b) alcohol improves sexual activity

c) only weak people of the character become alcoholic

d) consumption gives personality

$96 \%$ of young people have insufficient development of social skills, which is associated with the low capacity they have to resist the pressure of the group, the poor capacity of assertive communication to explain and defend their own opinions and behaviors as well as the presence of scarce resources for decision-making.

It has precisely identified that young people associate the cause of consuming alcoholic beverages mainly to the realization of recreational activities where alcohol is the basis for fun and has used to establish new relationships, as well as the need to be accepted by the group of friends.

These aspects are in correspondence with results obtained in other researches where it has shown that on different occasions the consumption of alcohol is not in correspondence with the young person really wants to do. However, they prefer to assume these behaviors to face the group rejection, and other Sometimes, it has been linked to reducing tension and uninhibited to improve social relationships at parties or say things that they normally fear expressing.

In addition, it has identified that habitually in the free time $87 \%$ of these young people prefer to meet to share or make parties where they occupy central place alcoholic beverages, since they consider that through consumption they get more stimulated and have total ignorance about an alcoholic cocktails, which is why alcohol becomes their only alternative.

There are no evident habits of performing leisure activities such as reading books, attending the theater and concerts, exhibitions and museums, among. Others, young people prefer to meet to share in the group but consuming a drink with the purpose of feeling relaxed, relieving the stress that the study produces and look for pleasure.

Taking into account the insufficiencies and educational needs identified in the initial diagnosis of the group, the following intervention program has designed:

\section{Psychoeducational intervention program to prevent alcohol abuse in the Student Residence}

The psychoeducational intervention program was designed in 7 sessions with an approximate duration of an hour and a half each. The program concludes with the realization by the group that participated in the Workshops of a Public Good Campaign that has the purpose of contributing to the prevention of alcohol consumption in the Student Residence. The program of psychoeducational intervention includes 4 components.

a) Cognitive: perception of risk on the short and long-term consequences of alcohol consumption.

b) Training in social skills: of a general nature and resistance to peer pressure for consumption.

c) Decision making: critical and reflective thinking to assume a responsible attitude towards alcohol consumption.

d) Leisure activities: alternatives to alcohol consumption to satisfy the search for new and varied sensations.

Collaborators with the Intervention Program.

a) Department of Psychology of the Student Residence of the Universidad de Oriente.

b) Specialists responsible for the University Extension Addiction Prevention Program.

c) Havana Club International Company.

Session \# 1 .

Topic: Presentation and initial diagnosis.

Objectives:

a) Create a favorable climate for group work by raising motivation and interest in the development of the sessions.

b) Awareness of the existing problem.

c) Methodological resources:

d) Presentation technique: the lit match.

Session \# 2.

Subject: Perception of risk and motivation for the change of the participants.

Objectives:

a) Analyze and reflect dynamically on beliefs, myths, and attitudes towards alcohol consumption. 
b) Facilitate the understanding of the effects associated with alcohol consumption.

c) Methodological resources:

d) Warm-up technique: "Get up and sit down".

e) Documentary video about alcohol and its effects on health (presentation of 3 cases in the video).

f) Questions to guide reflection and debate. (Situation Analysis Technique)

\section{Session \# 3.}

Topic: Social skills training.

Objectives:

a) Promote social skills required in situations of alcohol offer.

b) Promote attitudes to non-consumption and improve coping with risk situations.

c) Encourage critical and independent thinking as a method to guide our behavior.

d) Identify the possible emerging change in these young people.

Methodological resources:

a) Animation technique: The rally

b) Participative technique: Roleplay (representation of 3 scenes that require resisting the pressure of the group and the media)

c) Questions to guide reflection and debate.

\section{Session \# 4.}

Topic: Decision-making.

Objectives: To

a) Enhance the critical capacity and the decision-making before the group, maintaining an assertive communication.

b) Train autonomy, safety, and responsibility in decision-making.

Methodological resources:

a) Animation technique: The rolled ball

b) Participation technique: case analysis.

\section{Session \# 5 .}

Theme: Leisure activities.

Objectives:

a) Propose healthy alternatives for the use of free time as protective factors against alcohol consumption patterns.

b) Evaluate leisure alternatives in which alcohol consumption is not necessary.

c) Evaluate emerging changes in young people.

Methodological resources:

a) Warming technique: Sea and offshore

b) Participation technique: cake and brainstorming.

\section{Session \# 6.}

Topic: Training in alcoholic cocktails.

Objectives:

a) Master healthy alternatives to alcohol consumption.

b) Promote an alcoholic culture in young people.

Methodological resources:

a) Slides and practical demonstrations of specialists in the subject.

\section{Session \# 7.}

Theme: Final Evaluation and Orientation of the Impact Activity.

Objectives:

a) Assess the effectiveness of the strategy developed.

b) Guide the group to conduct a Public Good Campaign to prevent alcohol consumption in the Student Residence of the Universidad de Oriente.

Methodological resources:

a) Warm-up technique: Past, Present, and Future. 
b) Psychological assessment instruments: Composition, Risk Perception Questionnaire on Alcohol Consumption, Social Skills Questionnaire and Decision Making, Preference Questionnaire for leisure time.

c) Closing technique: The three chairs.

\section{Conclusions}

The group identified that alcohol consumption is an essential element in free time, and young people consider that through it they can stimulate and have fun, and have no knowledge of alcoholic cocktails that allow them to think of another alternative.

The increase in consumption is associated with the low perception of risk on the harmful effects of alcohol, as well as poor development of social skills that help young people to reject the pressure of the group. The psychoeducational strategy that has designed makes it possible to prevent the consumption of alcohol in university students in the Student Residence. It facilitates the assimilation of information about the effects of alcohol consumption and promotes the development of social skills necessary for students to make healthy decisions about alcohol. It promotes favorable attitudes towards non-consumption and motivation towards healthier lifestyles.

\section{References}

Aghara, V. N. O., Nwaizugbo, I. C., Oparah, P. C., \& Ifeanyichukwu, C. D. (2018). Sales promotion as a leverage strategy for improving sales and profitability in alcohol beverage industry. International Research Journal of Management, IT and Social Sciences, 5(4), 18-25. https://doi.org/10.21744/irjmis.v5n4.245

Ekawati, C., Adiputra, N., Sudewi, R., \& Duarsa, D. P. P. (2017). The effect of health education towards knowledge and teenager attitudes in consuming liquor, Kupang City in 2016. International Research Journal of Engineering, IT \& Scientific Research, 3(4), 20-26.

Ekawati, C., Agustina, -, Dukabaen, O., \& Telan, A. B. (2017). The influence of the 5 A's intervention towards teenagers attitude in consuming liquor at Kupang City. International Research Journal of Engineering, IT \& Scientific Research, 3(5), 58-65.

Estevez, AG, Roche, JRF, Espinosa, AHR, \& Rodríguez, DL (2018). Social skills training program to prevent alcohol in university students. International Journal of Health Sciences, 2(3), 4354. https://doi.org/10.29332/ijhs.v2n3.216

Estevez, AG, Roche, JRF, Saborit, AR, Espinosa, AHR, \& Rodriguez, DL (2019). Relationship between social skills and alcohol. International Journal of Health Sciences , 3 (1), 1-8. https://doi.org/10.29332/ijhs.v3n1.244

García del Castillo J. (2012). Concept of perception of risk and its impact on addictions. Health and Drugs. Vol. 12, $\mathrm{n}^{\circ} 2$.

González, R and Galán, G. (2007). Alcohol: the drug under the skin of the lamb. Rev. Hosp. Psychiatric Hospital of Havana, [series on the Internet]. Revised on September 5, 2018. Available at: http://www.revistahph.sld.cu/hph0307/hph030707.html

González, R. (2012). Mission rescue of addicts. Guide for the relationship of help with addicts. Havana Cuba. Editions.

Mazorra A, Galano A. (2014). Sociopsychological characterization of the Student Residence of the Universidad de Oriente. Department of Psychology of the Student Residence of the Universidad de Oriente, Santiago de Cuba, Cuba.

Ministry of Higher Education (2014). National Program for the Prevention of Drug Abuse. Republic of Cuba.

MINSAP (1997). Program of prevention and control of alcoholism and other dependence drugs. Havana, Cuba.

Monjas Casares I. (2012). Teaching social interaction skills program for children and adolescents. Madrid: Ed. Sciences of preschool and special education.

Universidad de Oriente (2001). Program for the prevention of drug abuse. Santiago de Cuba. 